\title{
Análise dos conteúdos de Física moderna e contemporânea presentes em quatro coleções de livros didáticos aprovadas no PNLEM 2009 e nos PNLDS 2012, 2015 e 2018
}

\author{
Jonas Guimarães Paulo Neto \\ Instituto Federal de Educação, Ciência e Tecnologia do Ceará (IFCE) - Campus Sobral \\ (jonasgui1@hotmail.com) \\ Antônio Nunes de Oliveira \\ Instituto Federal de Educação, Ciência e Tecnologia do Ceará (IFCE) - Campus Sobral \\ (nunesifsobral@gmail.com) \\ Marcos Cirineu Aguiar Siqueira \\ Instituto Federal de Educação, Ciência e Tecnologia do Ceará (IFCE) - Campus Maracanaú \\ (mcirineu@gmail.com)
}

\begin{abstract}
Resumo: Considerando a crescente discussão iniciada no final do século passado sobre a inserção de conteúdos de Física Moderna e Contemporânea no Ensino Médio, as pesquisas da área têm indicado a necessidade desses conteúdos no currículo da Educação Básica e nos livros didáticos. A presente pesquisa busca verificar como tais conteúdos são apresentados em quatro coleções aprovadas no PNLEM 2009 e nos PNLDs 2012, 2015 e 2018. A partir de uma pesquisa qualitativa realizada por meio de um estudo bibliográfico, análise de livros do Ensino Médio e trabalhos publicados na área, investigou-se como tais conteúdos são apresentados nos livros aprovados e como ocorreram as mudanças em suas atualizações, tencionando saber quais temas vêm sendo contemplados e de que forma são apresentados. Os resultados mostram que tópicos de Física Moderna e Contemporânea aparecem predominantemente no final do volume 3 de cada coleção e que, em algumas delas, foram suprimidos alguns temas no decorrer de suas atualizações. As mudanças mais significativas ocorreram na atualização das coleções do PNLEM 2009 para o PNLD 2012, período em que foram realizadas as principais adequações, visando ao Exame Nacional do Ensino Médio.
\end{abstract}

Palavras-chave: Física Moderna e Contemporânea; Ensino Médio; PNLD, Livro Didático.

\section{Analysis of modern and contemporary Physics contents in four paper collections approved in PNLEM 2009 and PNLD'S 2012, 2015 and 2018}

Abstract: Considering the growing debate begun at the end of the last century on the insertion of contents of Modern and Contemporary Physics in High School, the researches of the area which have successively indicated the necessity of the presence of this type of content in the basic education curriculum and the importance of the textbook, this research seeks to verify how such contents are presented in four collections approved in PNLEM 2009 and in PNLD's 2012, 2015 and 2018. Through a qualitative research carried out through a bibliographic study, analysis of high school books and published works in the area, we investigate how such contents are presented in the approved books and how the changes occurred in their successive updates aiming to know what themes are being contemplated and how they are presented. The results show that topics of Modern and Contemporary Physics appear predominantly at the end of volume 3 of each collection and that in some of them some were suppressed in the course of their updates. The most significant changes occurred in the updating of the PNLEM 2009 collections for PNLD 2012 during which time the main adjustments were made for the National High School Examination.

Key-words: Modern and Contemporary Physics, High School, PNLD, Didactic Book. 


\section{INTRODUÇÃO}

Em nosso Ensino Básico, a Física é geralmente ensinada em apenas um semestre nos anos finais da primeira etapa e ao longo dos três anos da segunda etapa, sendo geralmente dividida em tópicos: Mecânica, Física Térmica, Ondas, Óptica e Eletromagnetismo. Essa sequência é a mesma na maioria dos livros e manuais didáticos utilizados no Brasil. Recentemente, conteúdos de Física Moderna e Contemporânea (FMC) têm sido adicionados aos livros e, mediante novas pesquisas na área, têm surgido diversas propostas de ensino. Porém, o que se observa é que tais conteúdos estão, em sua maioria, ausentes das salas de aula na Educação Básica.

Tradicionalmente, a Física é dividida de acordo com três grandes fases: a Física Clássica, a Física Moderna e a Física Contemporânea. A Física Clássica, que compreende as teorias clássicas da Mecânica, Termodinâmica e Eletromagnetismo, fundamenta-se principalmente nos trabalhos desenvolvidos por cientistas como Kepler (1571 - 1630), Galileu (1564 - 1642), Newton (1643 - 1727), Carnot (1796 1832), Gauss (1777 - 1855), Faraday (1791 - 1867), Ampère (1775 - 1836) e Maxwell (1831 - 1879). Já a Física Moderna, que tem origem nas tentativas de se explicar as assimetrias detectadas entre as teorias clássicas ou entre elas e os experimentos, surge a partir dos trabalhos revolucionários de cientistas como Max Planck (1858 - 1947) e Albert Einstein (1879 - 1955). Seus trabalhos, publicados entre 1900 e 1916, nos levaram, entre outras coisas, a questionar sobre como a energia estaria distribuída no espaço (quantização) e trouxeram novas compreensões a respeito do tempo, do espaço, da massa e da energia. Finalmente, a Física Contemporânea, por sua vez, fundamenta-se nos principais resultados da Física Moderna e inclui assuntos como o teletransporte quântico, bóson de Higgs e as ondas gravitacionais.

Ostermann e Moreira (1998), a partir de uma técnica de consulta conhecida como Delphi, tentaram estabelecer junto à comunidade brasileira de professores e pesquisadores em ensino de Física os temas de FMC que poderiam estar presentes no Ensino Médio (EM). Tais autores concluíram que tópicos como: Efeito Fotoelétrico, Átomo de Bohr, Leis de Conservação, Radioatividade, Forças Fundamentais, Dualidade Onda-Partícula, Fissão e Fusão Nuclear, Origens do Universo, Raio-X, Metais e Isolantes, Semicondutores, Laser, Supercondutores, 
Partículas Elementares, Relatividade Restrita, Big-Bang, Estrutura Molecular e Fibras Ópticas poderiam ser contemplados no currículo.

Ao falarmos sobre a inserção da FMC no EM, devemos levar em consideração o livro didático que chega às escolas públicas, uma vez que este cumpre um papel decisivo ao subsidiar o trabalho do professor em sala de aula e, neste contexto, caracteriza-se como um elemento norteador do ensino-aprendizado. Devido a sua importância, surgiram diversos estudos voltados para análise da qualidade do livro didático, em meio aos quais podemos destacar aquele que é realizado pelo Ministério da Educação (MEC) por meio do Plano Nacional do Livro Didático (PNLD), que tem a reponsabilidade de selecionar as possíveis obras com perfis para serem utilizadas pelas escolas públicas brasileiras.

Antes do PNLD, o Plano Nacional do Livro Didático para o Ensino Médio (PNLEM) é que fazia essa análise. Hoje, esse último é um desdobramento do PNLD, sendo instituído pela Resolução CD FNDE no. 38, de 15/10/2003 (BRASIL, 2003) e inserido nele, de modo que, atualmente, utiliza-se apenas PNLD para designar o sistema de análise e distribuição de livros didáticos nas escolas públicas.

Os Guias produzidos para o EM são os documentos elaborados pelo PNLD que contêm as análises das coleções dos livros didáticos de todas as disciplinas desse nível. Os Guias de Física, portanto, discorrem sobre a Física no EM, os critérios utilizados na avaliação das coleções e apresentam as resenhas da análise das coleções aprovadas no programa, as quais estarão à disposição do professor para que ele faça a sua própria análise e escolha a que julgar mais adequada à sua realidade e necessidade. As resenhas estão organizadas em quatro seções:

Visão Geral, que faz uma breve apresentação da coleção, destacando os elementos que melhor a identificam; Descrição da obra, que apresenta a estrutura geral da coleção, as diferentes seções que a compõem e a organização dos conteúdos trabalhados; Análise da obra, destacando aspectos da proposta didáticopedagógica da coleção, da organização do conteúdo abordado e do Manual do Professor, além de eventuais ressalvas e outros elementos pertinentes à coleção em análise; e Em sala de aula, que oferece algumas orientações práticas ao professor para 0 desenvolvimento dos conteúdos e atividades propostos pela coleção. (BRASIL, 2017, p. 8)

Embora os livros que chegam ao EM sejam analisados pelo PNLD, quem seleciona um entre os aprovados são os professores atuantes em cada escola, assim, é importante que eles estejam cientes das necessidades educacionais atuais 
e capacitados a realizar uma análise crítica dos livros, percebendo qual se enquadra no perfil do estudante que se pretende formar. Para Sales (2014, p. 55), "é muito importante incluir na formação dos professores (e aqui a defesa vale tanto para a formação inicial como a continuada) uma discussão sobre os livros didáticos".

Segundo Morais e Guerra (2013), já no início dos anos 2000, os temas de FMC se faziam presentes na maioria dos livros didáticos, indicando, no mínimo, a intenção em incluí-los nas aulas de Física. Porém, o fato de esses conteúdos serem colocados, em sua maior parte, nos capítulos finais dos volumes 3 dos livros, após o estudo dos temas mais tradicionais da Física Clássica, e de forma muito sucinta, não contribui com as abordagens dos professores que seguem rigorosamente o livro texto. Isso porque eles costumam se deparar com dois problemas persistentes: a falta de tempo para incluir mais um conteúdo no seu planejamento já tão extenso, e a sensação de falta de preparo para lidar com o tema.

A forma como os conteúdos de Física são apresentados na maioria dos livros acarreta o distanciamento dos alunos com relação à discussão de temas atuais, haja vista que os conteúdos de FMC, que são, geralmente, a única alternativa pra elucidar os temas que estão em debates na atualidade e que despertam a curiosidade dos estudantes, costumam ser trabalhados apenas no último volume dos livros e de uma forma excessivamente resumida e rápida.

Ao comparar o estágio atual de desenvolvimento científico e tecnológico com a situação do ensino de Física nas escolas do EM, percebe-se por meio de uma análise superficial do currículo desse nível que, embora estejamos vivendo no século XXI e que muitas descobertas relevantes e construções revolucionárias tenham sido concretizadas desde o final do século XIX, as nossas escolas continuam com um currículo onde a Física ensinada é predominantemente (quase que exclusivamente em algumas escolas) aquela desenvolvida anteriormente ao século XX. Nesse ínterim, afloram os questionamentos: os livros didáticos corroboram no sentido de possibilitar a inserção de FMC no EM? Como eles costumam estruturar os conteúdos de Física a serem ensinados pelo professor?

Frente a esses questionamentos, tendo em vista a importância do livro didático no ambiente escolar e considerando a necessidade da inclusão de tópicos de FMC no EM, pretende-se realizar uma análise das coleções destinadas a esta etapa de ensino com foco naquelas que foram aprovadas no PNLEM 2009 e nos PNLD's 2012, 2015 e 2018, de forma a observar quais tópicos vêm sendo 
contemplados, verificar se suas abordagens favorecem a introdução de FMC em sala de aula e comparar as abordagens textuais com as propostas indicadas na literatura pelos pesquisadores da área, as quais estão intrinsecamente ligadas à essa problemática e visam orientar a implementação desses conteúdos.

\section{METODOLOGIA}

A pesquisa caracteriza-se como um estudo exploratório de abordagem qualitativa, diante do objetivo de discutir tendências e opiniões parcialmente contempladas pela literatura, e se realiza mediante a análise do volume 3 dos livros de Física aprovados no PNLEM do ano de 2009 e no PNLD dos anos 2012, 2015 e 2018 acerca da introdução de tópicos de FMC no EM.

Foram pesquisados os volumes 3 de quatro das principais coleções de Física dedicadas ao EM. Com base na literatura do tema de pesquisa, os tópicos de FMC se encontravam dispostos exclusivamente em tais volumes, os últimos livros das coleções destinadas aos alunos desse nível de ensino. O critério utilizado foi que a mesma coleção a ser analisada tivesse sido aprovada nos últimos quatro programas nacionais que se destinam a esse fim, o PNLEM 2009, e os PNLD's 2012, 2015 e 2018. Após uma busca em escolas públicas e na internet, foram encontrados os quatro livros (volume 3) de quatro coleções com essa característica. Dessa forma, foram analisados 16 livros ao todo. Algumas coleções sofreram alteração no nome e/ou na editora, bem como alguns autores foram incluídos ou excluídos. Entretanto, foram consideradas as mesmas coleções didáticas visto que esses fatores não ocasionaram mudanças que lhes fizessem parecer diferentes, ou seja, continuaram com sua essência própria.

A análise dos livros foi feita com o intuito de observar quais conteúdos de FMC estão presentes nas coleções, como se deu a introdução desses temas ao longo de suas atualizações, a opinião dos autores acerca dessa inserção e as características de cada coleção ao tratar esses tópicos, como a contextualização do conteúdo, a utilização de figuras ilustrativas ou quadros adicionais e a indicação de experimentos e vídeos didáticos, bem como se os livros instigam a curiosidade dos estudantes. Os exercícios também foram levados em consideração, tanto a quantidade quanto a forma como são apresentados, abertos, sem itens para marcar, 
ou objetivos, com itens de marcar. Foram elaborados quadros para facilitar a visualização dos resultados encontrados.

O PNLEM 2009 e os PLND's 2012, 2015 e 2018 foram tomados como referência para a análise do volume 3 de cada coleção devido à sua grande importância para a manutenção da educação do país, avaliando, indicando e distribuindo livros didáticos de qualidade para as escolas públicas. Segundo Mota (2018), o mais importante do PNLD é que "esse material tem sido o grande orientador dos professores na condução de suas aulas na educação básica". Portanto, como os Guias são elaborados pelos programas, preferiu-se tomá-los como base para realizar a análise dos livros, contrastando com as observações feitas sobre a abordagem de FMC e os trabalhos de autores com o mesmo enfoque. Nesse sentido, a análise crítica e aprofundada do conteúdo de tais Guias foi deixada para uma próxima pesquisa.

É muito importante a elaboração desses Guias pelo governo, para que todos os professores da rede pública possam ter acesso a uma avaliação feita por professores de Física com experiência na área. Esses documentos, além das resenhas dos livros, contêm todos os critérios utilizados na análise das coleções. Dessa forma, o professor se depara com bons livros de Física e com uma síntese de suas abordagens. A última edição do Guia, PNLD 2018 (BRASIL, 2017), além disso, contém também um espaço para discutir o ensino de Física no EM, discorrendo sobre assuntos como a contextualização prática aplicada no ensino de Física, a resolução de problemas, atividades experimentais, atividades investigativas e a utilização de recursos computacionais.

Como não há um consenso entre os autores das coleções de livros didáticos acerca de quais tópicos de FMC devem estar presentes nos livros, foi utilizada a lista elaborada por Ostermann e Moreira (1998) citada anteriormente, pois não foi encontrado nenhum outro trabalho com esse objetivo, e considerou-se, além disso, a importância da pesquisa dos autores para o tema. 


\section{RESULTADOS E DISCUSSÃO}

Haja vista a discussão acerca da presença de tópicos de FMC nos livros didáticos de Física destinados ao EM, apresenta-se, em seguida, a análise de quatro coleções que estão presentes do PNLEM 2009 e PLND’s 2012, 2015 e 2018.

\section{Compreendendo a Física - Alberto Gaspar - Editora Ática}

Esta coleção está presente no EM desde o PNLEM 2009, com o mesmo autor e editora. Na edição do PNLEM 2009, o livro se chamava Física, volume único. Já nas edições do PNLD 2012, PNLD 2015 e PNLD 2018, a coleção é composta de três volumes e é intitulada Compreendendo a Física, sendo $1^{\underline{a}}, 2^{\underline{a}}$ e $3^{\underline{a}}$ edição, respectivamente.

A edição Física (GASPAR, 2005a) é dividida em quatro unidades: Mecânica; Ondas e Óptica; Termodinâmica e Eletromagnetismo. O conteúdo de FM é abordado no último capítulo e não é vinculado a nenhuma das unidades anteriores. No catálogo do PNLEM 2009 não há informações sobre a presença ou não da FM nessa obra. O manual do professor ressalta que o livro apresenta um panorama da Física atual construída no século XX. Trata-se de uma breve abordagem com algumas ideias que o autor considera mais relevantes para o EM (DOMINGUINI, 2012). O autor defende enfaticamente a inserção da FM no EM:

É muito importante que o professor tente apresentá-lo aos seus alunos. A inexistência de qualquer referência à física moderna no Ensino Médio é tão absurda como insustentável. Não é possível que se ensine uma ciência com uma desatualização de quase 150 anos. (GASPAR, 2005b, p. 4)

Para ele, o fato de serem ideias difíceis de se compreender ou haver necessidade de uma matemática avançada não são argumentos razoáveis para excluir esse conteúdo do EM. Ainda segundo ele, qualquer conteúdo de Física pode tornar-se complexo o bastante dependendo da abordagem utilizada. Compreende que o professor precisa dispor-se e enfrentar seus medos para que a FM possa ser inserida no EM.

Nas edições do PNLD 2012 (GASPAR, 2011), PNLD 2015 (GASPAR, 2013) e PNLD 2018 (GASPAR, 2017) são reservados três capítulos para a FMC, chamados: "Relatividade", "As origens da Física Quântica" e "A nova Física", passando a 
abordar tais conteúdos com a mesma forma e importância que os de Física Clássica. A partir da $2^{\underline{a}}$ edição, o livro passou a ser dividido em unidades, nas quais esses três capítulos compõem a unidade intitulada "Física Moderna". As unidades se iniciam com um texto introdutório sobre um dos motivos a partir dos quais se justifica uma "nova Física". Nas três edições, os capítulos possuem um breve texto falando sobre obras literárias de divulgação científica relacionadas ao estudo de FMC, observações e consequências do estudo em questão. Segundo Maximiniano, Cardoso e Dominguini (2013), quando fizeram uma análise das coleções de Física do PNLD 2012, além de três capítulos situados no final do volume 3, o autor da coleção analisada traz diversos textos sobre a FM nos demais volumes. Eles acrescentam, ainda, que é evidente a evolução na abordagem dos conteúdos de FM pelo autor, quando comparados aos programas PNLEM 2009 e PNLD 2012. Esses textos são importantes para que a FMC tome espaço nos demais volumes, no entanto, ainda têm caráter complementar. Os volumes 1 e 2 ainda não reservam tópicos ou capítulos para tratar realmente desses assuntos.

No primeiro capítulo, que aborda a Teoria da Relatividade, um subtópico foi adicionado na $2^{\underline{a}}$ e na $3^{\underline{a}}$ edição, o qual trata de aspectos históricos sobre a vida do cientista Albert Einstein e percebe-se nele a inserção de novos textos, sendo que um deles é referente à Relatividade Geral. Já no fim do capítulo, há um quadro chamado "Atividade Prática", que sugere uma atividade e ensina o passo a passo, com ajuda de ilustrações, como realizá-la. Entretanto, apenas na $1^{\text {ạ }}$ edição há cinco páginas chamadas "Conhecendo um pouco mais..." com conhecimentos e informações que complementam o processo de ensino e aprendizagem. As ilustrações são praticamente as mesmas nas três edições.

Para o Guia do PNLD 2012, a inserção da FM feita pelo autor se demonstra satisfatória. Entretanto, há uma exceção que é "o tratamento dado ao conceito de simultaneidade, apresentado como uma impossibilidade, na introdução ao tratamento da relatividade restrita, quando seria mais apropriado ressaltar seu caráter relativo" (BRASIL, 2011, p. 31).

Dentro do segundo capítulo, percebe-se que, na última edição, não há um certo tópico, chamado "O enigma do espectro da radiação térmica", presente nas duas edições anteriores. Além disso, nessa edição a quantidade de exercícios resolvidos e propostos aos alunos é reduzida. Um ponto muito importante nesse capítulo é que, nas duas últimas edições, há várias biografias pequenas dos 
cientistas que foram importantes no desenvolvimento da FQ, distribuídas ao longo do capítulo. $\mathrm{Na} 1^{\text {a }}$ edição é reservado o quadro "Conhecendo um pouco mais..." para falar sobre eles. No final de cada capítulo da $1^{\text {a }}$ edição há um quadro chamado "Atividades" que expõe o mesmo experimento do quadro "Atividade Prática" das outras duas edições. Segundo o Guia do PNLD 2018, "há um destaque para as atividades práticas, que estão presentes ao final de cada capítulo e cumprem com suas finalidades essenciais" (BRASIL, 2017, p. 40). Em síntese, alguns textos mudaram de lugar ou nome durante o capítulo e a $1^{\text {a }}$ edição contém um tópico e também exercícios a menos que a $2^{\underline{a}}$ e $3^{\underline{a}}$ edições.

No último capítulo, a $1^{\underline{a}}$ e $2^{\underline{a}}$ edições têm dois tópicos a mais que a $3^{\underline{a}}$ edição, que são "O nêutron e o pósitron" e "O núcleo atômico e a energia nuclear", enquanto na $1^{a}$ não consta o subtópico "A descoberta dos Quarks", presente nas duas mais recentes. As duas últimas edições contêm vários quadros com informações complementares e não há atividade prática proposta na 3ª edição, concluindo que nesse capítulo a $2^{2}$ edição é mais completa quanto ao conteúdo.

Nos três capítulos da $1^{1 \mathfrak{a}}$ edição há questões de vestibular propostas para os estudantes fazerem, já nas outras edições esses exercícios estão presentes apenas no último capítulo do livro. Os exercícios são praticamente os mesmos nos três capítulos das três edições, porém a última edição possui menos questões resolvidas e propostas. Ao longo dos capítulos, há um boxe chamado "Conexões" que, segundo o Guia do PNLD 2015, "busca estabelecer relações com outras disciplinas do currículo escolar" (BRASIL, 2014, p. 34). Para o Guia, a obra "contempla de forma equilibrada o conjunto de conhecimentos da Física, apresentando os conteúdos tradicionais e com uma boa exposição da Física Moderna" (BRASIL, 2014, p. 36).

Percebe-se que, ao longo das atualizações dos livros, alguns tópicos são inseridos e outros são excluídos, além do que as mudanças mais significativas foram da edição do PNLEM 2009 para o PNLD 2012. Outro ponto de destaque é a inserção de informações complementares nas últimas atualizações, complementando o conteúdo dos capítulos. As atividades práticas também recebem bastante atenção do autor, reforçando a experimentação nas aulas de Física. Deste modo, observa-se que a postura dele é favorável à inserção da FMC no EM, pois reservou espaço para esses conteúdos dentro da sua obra. Entretanto, ressalta-se 
que mais temas de FMC poderiam estar presentes nos livros, já que essa área da Física não se restringe apenas ao estudo das TR e da FQ.

\section{Física Interação e Tecnologia - Gonçalves Filho e Toscano - Editora Leya}

As coleções destes autores estão presentes no EM desde o PNLEM 2009, porém houve alterações na editora e nos nomes das coleções. Essas alterações, contudo, não afetaram a essência do trabalho, que teve visível continuidade. As obras do PNLEM 2009 e do PNLD 2012 foram lançadas pela Scipione na 1a edição cada. No primeiro programa, a coleção se chamava Física (GONÇALVES FILHO; TOSCANO, 2007) e, no segundo programa, se chamava Física e Realidade (GONÇALVES FILHO; TOSCANO, 2011). Já nas edições do PNLD 2015 e PNLD 2018, a editora é Leya, possuindo $1^{\underline{a}}$ e $2^{\underline{a}}$ edições, e ela passa a se chamar Física Intergeração e Tecnologia (GONÇALVES FILHO; TOSCANO, 2013, 2016).

A edição do PNLEM 2009 não apresenta em seu índice nenhuma menção a um capítulo, unidade, apêndice ou anexo específico para a FM. A obra é em volume único e está dividida em três grandes unidades: Mecânica; Física Térmica e Óptica; Eletricidade e Magnetismo. Na versão estudante do livro, o autor faz uma menção à FM na introdução do livro, expondo a Física como uma ciência em transformação que investiga os fenômenos da natureza, sendo que, no campo da pesquisa, relaciona-se diretamente com as demais ciências naturais, como a Química, a Astronomia e a Biologia (DOMINGUINI, 2012). Segundo o catálogo do PNLEM 2009, "os elementos da Física Contemporânea são distribuídos ao longo da obra, relacionando-os aos conteúdos tratados" (BRASIL, 2008, p. 56). Porém, Dominguini (2012) atesta que tal menção se encontra na seção "Texto e Interpretação", de leitura complementar.

A partir da edição do PNLD 2012, as coleções passaram a ser divididas em 3 volumes. Em todas, é reservado o último capítulo, que é equivalente à uma unidade, para falar sobre FMC, intitulado "Tópicos de Física Moderna", e é dividido em quatro tópicos, equivalentes aos capítulos, havendo mudança apenas na nomenclatura de alguns, continuando a mesma essência, sendo eles, na última atualização: "Uma nova maneira de compreender o mundo físico", "A física moderna e as novas tecnologias", "Da radioatividade às radioterapias" e "O núcleo atômico". 
A coleção Física e Realidade traz em todos os capítulos dos três volumes da coleção uma seção intitulada "Texto e interpretação", que consiste de um texto seguido de questões, no qual os autores expõem de que maneira o assunto estudado no capítulo sofreu alterações após o surgimento da FM. Além do mais, explicam mais detalhadamente como os princípios da Física, recém-estudados, são aplicados em aparatos tecnológicos (MAXIMINIANO CARDOSO; DOMINGUINI, 2013).

Para Maximiniano, Cardoso e Dominguini (2013), em relação à obra de 2012, percebe-se uma evolução na forma de estruturar os conteúdos de FM pelos autores, notando-se uma postura favorável à inserção desse conteúdo no EM. Entretanto, alguns aspectos básicos da FM devem ser abordados por meio de outras fontes, pois tal conteúdo não se encontra disponível no livro didático.

Analisando os capítulos de FM das últimas três edições, pode-se perceber que as mudanças não foram significativas, mas apenas nas duas últimas edições do PNLD há um novo subtópico chamado "O surgimento da Física Quântica", no restante, há apenas algumas diferenças na estruturação dos textos e figuras. Há exercícios resolvidos e propostos no final dos capítulos e os "Exercícios de revisão", encontrados no final do desenvolvimento dos capítulos para reforçar a aprendizagem dos conteúdos.

No decorrer dos capítulos, há alguns quadros que complementam o conteúdo, como: "Algo a +", que são boxes de leitura para ampliar os conteúdos tratados, e "Texto e Interpretação", que são boxes que abordam aspectos históricos, controvérsias científicas e contexto social da produção de conhecimento. No fim de cada capítulo há um quadro chamado "Na Internet", com indicações de sites que contemplam conteúdos, simuladores e vídeos que podem ser trabalhados on-line, e no final de cada livro um outro quadro chamado "Projetos", que tem como objetivo contextualizar e integrar os temas da Física com as demais disciplinas.

Segundo o Guia do PNLD 2015 (BRASIL, 2014, p. 74), a "estrutura diferenciase dos livros didáticos convencionais. Por exemplo, conteúdos de Física Moderna são tratados ao longo de todos os volumes e os conceitos de dinâmica antecedem e são privilegiados em relação aos de cinemática”. Já para o Guia do PNLD 2018 (BRASIL, 2017):

A obra contempla e apresenta de forma adequada conhecimentos usualmente classificados como de Física Moderna e 
Contemporânea, os quais se encontram quase inteiramente reunidos no último capítulo do volume III. No entanto, ainda que de forma bastante pontual, algumas ideias da Física Moderna aparecem em inserções da seção Texto e interpretação presentes nos demais volumes. (BRASIL, 2017, p. 68)

Constata-se que, assim como na coleção anterior, as principais mudanças nessa coleção são referentes à passagem da edição do PNLEM 2009 para o PNLD 2012, mostrando que os autores são favoráveis à introdução de temas de FMC no EM, os quais trazem conteúdos complementares de FM durante os 3 volumes. É interessante citar a estrutura da coleção quanto à divisão entre unidades e capítulos, além da troca na ordem de alguns conteúdos que classicamente vêm nos livros. Contudo, a abordagem feita pelos autores não se assemelha às de outras coleções didáticas, pois elas não trazem com detalhes os tópicos mais comuns, Relatividade e $F Q$, focando numa abordagem mais geral, conceitual e voltada para as transformações ocorridas após o desenvolvimento da FMC, bem como para as suas aplicações tecnológicas.

Física: Contexto e Aplicações - Máximo, Alvarenga e Guimarães - Editora Scipione

Esta coleção foi sofrendo mudanças na sua nomenclatura durante os programas e houve a inclusão de um novo autor. Está presente no EM desde o PNLEM 2009, com o nome Física (MÁXIMO; ALVARENGA, 2005). No PLND 2012, o nome mudou para Curso de Física (MÁXIMO; ALVARENGA, 2011) e no PNLD 2015 para Física Contexto e Aplicações (MÁXIMO; ALVARENGA, 2014), sendo esta última renovada para a 2 $2^{\mathrm{a}}$ edição para o PNLD 2018 (MÁXIMO; ALVARENGA; GUIMARÃES, 2016). A grande diferença entre as coleções se dá entre a edição do PNLEM 2009 e todas as outras.

Na edição do PNLEM 2009 é reservado o último capítulo do volume 3 para falar um pouco sobre FMC, intitulado de "A nova Física", o qual é composto pelos tópicos: Uma visão panorâmica; O mundo do muito pequeno - Quais são as partículas elementares; $O$ mundo do muito grande; e $O$ mundo das estruturas complexas. Trata-se de um capítulo curto, com apenas 11 páginas, no qual, segundo Dominguini (2010), os autores apresentavam a FM como um assunto complementar à formação regular. 
Nas últimas três edições é reservada uma unidade para abordar tópicos de FMC, em consonância com o posicionamento de Dominguini (2010), sendo iniciada por um breve texto introdutório do conteúdo nas edições do PNLD 2015 e 2018 e possuindo um capítulo, chamado "Teoria da Relatividade e Física Quântica". Como introdução do capítulo, as duas edições do Física Contexto e Aplicações possuem um pequeno texto, diferentes em ambas, mas na $2^{\underline{a}}$ edição não há mais um tópico chamado "Uma visão panorâmica", que consiste de um resumo do que será visto no decorrer do capítulo.

Justificando esse novo posicionamento, os autores afirmam, por exemplo, que a apresentação de tópicos de FM, como nanociência e cosmologia, tem por objetivo preparar o aluno para se posicionar em relação a essas pesquisas, tanto em termos de financiamento público como em relação à importância delas para sua realidade (MÁXIMO; ALVARENGA, 2010). Embora apresente esse conteúdo estruturado nos capítulos finais de sua obra, os autores também trazem os textos de FM dispersos ao longo dos três volumes. Tal informação é evidenciada pelo Guia do PNLD 2012, ressaltando que

assuntos relativos à Física Moderna e Contemporânea são abordados em vários momentos da obra e, com exclusividade nos dois capítulos finais do $3^{\circ}$ volume. É o caso, por exemplo, da energia relativística tratada no $1^{\circ}$ volume; de conceitos envolvidos no estudo da radiação do corpo negro e dos espectros atômicos, abordados no $2^{\circ}$ volume; e de conteúdos sobre quantização de carga elétrica e sobre transistores tratados no $3^{\circ}$ volume. (BRASIL, 2011, p. 36)

A edição Curso de Física possui oito tópicos que não estão presentes nas duas edições seguintes, sendo eles: O fóton; Ideias básicas da Física Quântica; Princípios básicos da Física Quântica; Barreiras de potencial; A Nova Física; O mundo do muito pequeno - as partículas elementares; $O$ mundo muito grande e $O$ mundo das estruturas complexas, e ainda mais dois no apêndice: Relatividade Especial e Física Quântica. Em contrapartida, as edições do PNLD 2015 e 2018 possuem subtópicos não comuns com a do PNLD 2012, sendo eles: O "paradoxo" dos gêmeos; Nota sobre o conceito de massa e Massa de um feixe de luz. Ainda no fim da 1a edição do Física Contexto e Aplicações, há, em um quadro, um tópico suplementar e mais dois subtópicos, que fazem parte dos oito que foram citados anteriormente. Outro ponto de destaque da coleção Curso de Física é que ela possui várias biografias, embora curtas, de físicos importantes sobre o assunto que esteja sendo tratado no decorrer do capítulo. 
Há vários quadros nos livros, como Física no Cotidiano, que são aplicações dos conceitos e leis em contextos do dia a dia, presentes na coleção Curso de Física, Física no Contexto, que são leituras complementares, e Aplicações da Física, que são aplicações tecnológicas, ambos presentes nas duas edições da coleção Física Contexto e Aplicações. Algumas informações estão presentes nos três livros, porém, em quadros diferentes.

$\mathrm{Na}$ edição do PNLD 2012, há um quadro com exercícios de fixação no decorrer do capítulo. Nas outras duas, mais recentes, os exercícios com esse propósito estão em um quadro chamado "Verifique o que Aprendeu". No final do capítulo dos livros há mais exercícios e sugestões de experiências e há também, nas edições do PNLD 2015 e 2018, dois grandes quadros, chamados "Integrando... o fazer ciência ao mundo moderno", relacionando com outras áreas do conhecimento, e "Infográfico", que é apresentado no final de cada unidade.

A coleção analisada teve suas principais mudanças quando passou de Física para Curso de Física, embora na primeira versão os autores já tratassem, mesmo que com caráter complementar, de assuntos de FMC. Através das mudanças, é possível inferir a posição deles em relação ao ensino de FMC no EM, que se mostraram favoráveis a tal prática. A inserção e exclusão de alguns tópicos também foi percebida, principalmente da edição do PNLD 2012 para o PNLD 2015 e 2018. Os autores fazem um bom estudo da Relatividade e da FQ, bastante conceitual e considerando, especialmente, os aspectos teóricos que envolvem esses conteúdos, bem como a Física anterior a tais teorias e os problemas existentes que precederam seus surgimentos.

Física Ciência e Tecnologia - Torres, Ferraro, Soares e Penteado - Editora Moderna

Desde o PNLEM 2009 (PENTEADO; TORRES, 2005) esta coleção está presente no EM, havendo algumas alterações nos autores ao longo dos anos. Em todas as edições é reservada uma unidade para a FM. Na $1^{\text {a }}$ edição, que faz parte do PNLEM 2009, a unidade é composta de três capítulos, a saber: Relatividade Especial, Física Quântica e Física Nuclear. O Guia do PNLEM 2009 (BRASIL, 2008) ressalta que: 
Diferentemente do usual em textos didáticos de física para o Ensino Médio, a obra dá destaque à física moderna, dedicando a ela um espaço que corresponde mais que o dobro daquele dedicado, por exemplo, à cinemática. [...] não é apresentada como um apêndice, mas sim recebe toda uma unidade didática. (BRASIL, 2008, p. 27)

Os autores destacam, como objetivo do ensino da FM, permitir ao aluno a compreensão da dilatação temporal e da contração do espaço, as condições em que ocorre o efeito fotoelétrico, os postulados de Bohr sobre a estrutura da matéria e os mecanismos que explicam a radioatividade. Também apresentam uma seção denominada Aplicação Tecnológica para ressaltar que os conteúdos contidos no livro não estão distantes da realidade do aluno.

Nas outras três edições (TORRES; FERRARO; SOARES, 2010; TORRES et al., 2013, 2016), a unidade é composta de quatro capítulos, que são: Relatividade Especial, Física Quântica, Física Nuclear e Tecnologia das Comunicações. No primeiro capítulo, pode-se perceber uma redução de alguns tópicos comparando a 2ª , 3a e 4⿳亠丷a edição, do PNLD 2012, PNLD 2015 e PNLD 2018, respectivamente, e a adição de apenas um novo tópico que introduz o capítulo das últimas duas edições. $\mathrm{Na} 4^{a}$ edição, não há mais os tópicos "Transformações Galileanas", "Relatividade de Newton" e "Breve descrição da experiência de Michelson e Morley". Apesar das três últimas edições terem o nome "Relatividade Especial", todas têm o último tópico do capítulo intitulado "Noções de Relatividade Geral".

O aprofundamento dado pelos autores a esse conteúdo, comparando aos demais livros, é de qualidade superior e enfoca uma abordagem temática e interdisciplinar. Entretanto, o Guia, tomado aqui como ponto de partida para a análise, faz uma crítica à complexidade dos conteúdos, em que afirma que o tratamento dado a ele é "superior àquele que seria desejável para o Ensino Médio, assim se torna necessário que o professor faça adequações quanto à abordagem desses capítulos, tendo em vista o contexto de desenvolvimento de suas turmas" (BRASIL, 2011, p. 47). O Guia também afirma que a FM recebe uma abordagem temática e interdisciplinar e realça questões ambientais, o que "propicia condições para que os alunos tenham elementos para se posicionar frente aspectos emergentes na contemporaneidade, particularmente os relativos à poluição ocasionada pelo uso de diferentes fontes de energia" (BRASIL, 2011, p. 47). Segundo Maximiniano, Cardoso e Dominguini (2013), percebe-se que a FM é 
tratada com a mesma importância dada aos demais conteúdos, o que deixa claro que os autores defendem sua inserção no EM.

No segundo capítulo, Física Quântica, as alterações são mais relativas ao texto e figuras, havendo melhorias na $3^{\underline{a}}$ e $4^{a}$ edições, em comparação à $2^{\underline{a}}$. Em contrapartida, aquelas não possuem mais o tópico sobre semicondutores, diodos e transistores. No terceiro e último capítulos, as mudanças também são referentes ao texto e figuras, havendo trocas da nomenclatura dos tópicos, por exemplo. Porém, na 4a edição, não há mais o tópico sobre o fax, que foi muito utilizado antes da popularização do e-mail.

No que tange aos exercícios, houve a adição de algumas novas questões ao longo das edições e uma reestruturação nas suas posições. No decorrer dos capítulos, há quadros chamados "O que diz a mídia!" e "Aplicação Tecnológica" que complementam o livro. E no fim dos capítulos, há o "Navegue na Web", com links da internet sobre alguns assuntos, e o "Sugestões de leitura", com sugestões de textos que complementam o conhecimento.

Observa-se que, desde o PNLEM 2009, os autores mostram-se favoráveis à inserção de tópicos de FMC no EM, reservando uma unidade composta de 3 capítulos para o estudo desses temas e, posteriormente, expandindo esse número para 4 capítulos. Tal fato não foi percebido nas outras coleções analisadas. Além disso, percebeu-se também uma diminuição dos conteúdos à medida que o livro foi sendo atualizado. No entanto, a coleção também se destaca por ser bem mais conteudista que as outras, trazendo mais carga teórica em seus capítulos e um enfoque maior para as equações matemáticas que embasam as teorias. Na última edição, presente no PNLD 2018, a unidade Física Moderna e Contemporânea é composta por 96 páginas, apresentando-se como a coleção que mais reservou espaço, dentre as analisadas, para abordar conteúdos de FMC, e também se destaca por tal unidade possuir pouco mais que a metade do espaço que é destinado ao estudo do Eletromagnetismo, que é o conteúdo mais abordado no volume 3 das coleções didáticas de Física. 


\section{Análise dos dados das coleções didáticas}

O quadro 1 abaixo contém os capítulos de FMC nas coleções analisadas.

Quadro 1 - Conteúdos de FMC das obras analisadas.

\begin{tabular}{|c|c|c|c|c|}
\hline \multirow{2}{*}{ COLEÇÃO } & \multicolumn{4}{|c|}{ CAPÍTULOS } \\
\hline & PNLEM 2009 & PNLD 2012 & PNLD 2015 & PNLD 2018 \\
\hline \multirow{3}{*}{$\begin{array}{l}\text { Compreendendo } \\
\text { Física }\end{array}$} & \multirow{3}{*}{ 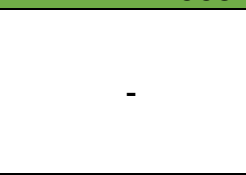 } & Relatividade & Relatividade & Relatividade \\
\hline & & $\begin{array}{l}\text { Origens da Física } \\
\text { Quântica }\end{array}$ & $\begin{array}{l}\text { Origens da Física } \\
\text { Quântica }\end{array}$ & $\begin{array}{l}\text { As origens da } \\
\text { Física Quântica }\end{array}$ \\
\hline & & A nova Física & A nova Física & A nova Física \\
\hline \multirow{4}{*}{$\begin{array}{l}\text { Física Interação } \\
\text { Tecnologia }\end{array}$} & \multirow{4}{*}{-} & $\begin{array}{l}\text { Um novo } \\
\text { paradigma }\end{array}$ & $\begin{array}{l}\text { Uma nova } \\
\text { maneira de } \\
\text { compreender o } \\
\text { mundo físico }\end{array}$ & $\begin{array}{l}\text { Uma nova } \\
\text { maneira de } \\
\text { compreender o } \\
\text { mundo físico }\end{array}$ \\
\hline & & $\begin{array}{l}\text { A Física Moderna } \\
\text { que podemos } \\
\text { encontrar no } \\
\text { laser, na cultura e } \\
\text { no } \\
\text { entretenimento }\end{array}$ & $\begin{array}{l}\text { A Física Moderna } \\
\text { e as novas } \\
\text { tecnologias }\end{array}$ & $\begin{array}{l}\text { A Física Moderna } \\
\text { e as novas } \\
\text { tecnologias }\end{array}$ \\
\hline & & $\begin{array}{l}\text { Da bomba } \\
\text { atômica à } \\
\text { radioterapia }\end{array}$ & $\begin{array}{l}\text { Da radioatividade } \\
\text { às radioterapias }\end{array}$ & $\begin{array}{l}\text { Da radioatividade } \\
\text { às radioterapias }\end{array}$ \\
\hline & & O núcleo atômico & O núcleo atômico & O núcleo atômico \\
\hline $\begin{array}{l}\text { Física Contexto } \\
\text { Aplicações }\end{array}$ & A nova Física & $\begin{array}{l}\text { Teoria da } \\
\text { Relatividade e } \\
\text { Física Quântica }\end{array}$ & $\begin{array}{l}\text { Teoria da } \\
\text { Relatividade e } \\
\text { Física Quântica }\end{array}$ & $\begin{array}{l}\text { Teoria da } \\
\text { Relatividade e } \\
\text { Física Quântica }\end{array}$ \\
\hline \multirow{2}{*}{$\begin{array}{l}\text { Física Ciência } \\
\text { Tecnologia }\end{array}$} & $\begin{array}{l}\text { Relatividade } \\
\text { Especial }\end{array}$ & $\begin{array}{l}\text { Relatividade } \\
\text { Especial }\end{array}$ & $\begin{array}{l}\text { Relatividade } \\
\text { Especial }\end{array}$ & $\begin{array}{l}\text { Relatividade } \\
\text { Especial }\end{array}$ \\
\hline & $\begin{array}{l}\text { Física } \\
\text { Quântica }\end{array}$ & Física Quântica & Física Quântica & Física Quântica \\
\hline
\end{tabular}

Fonte: Dados da pesquisa.

Como pode-se perceber, a Teoria da Relatividade e Física Quântica estão presentes em quase todas as obras. Entretanto, há temas que estão presentes na lista feita por Ostermann e Moreira (1998), como Origens do Universo, Semicondutores, Supercondutores, Partículas Elementares e Radioatividade, que são pouco contemplados ou não aparecem nos livros, os quais poderiam contribuir para a formação do aluno que está em conexão com o mundo em que vive. É importante acrescentar que os conteúdos de FC são, na maioria, os mesmos nas coleções analisadas, mostrando que as editoras e autores concordam em quais temas de FC devem figurar os livros.

Para que haja a inserção de FMC no EM, não é necessário excluir temas de FC considerados menos importantes, pois por mais que alguns tenham sido descobertos há muitos anos, a Ciência está em constante construção, o que justifica seu ensino. Os conteúdos de FMC podem ser inseridos em momentos oportunos 
durante $01^{\circ}$ ou $2^{\circ}$ ano do $E M$, não havendo a necessidade de esperar o último bimestre do $3^{0}$ ano para serem ensinados. Tal fato é um dos fatores que mais contribui para que não haja espaço para ensinar esses assuntos. Não se pretende deixar os professores do EM sobrecarregados de conteúdos para ensinar e nem desmerecer outros assuntos da Física, o que se defende aqui é que haja uma definição de quais conteúdos devem constar neste nível de ensino e quais as melhores metodologias para uma inserção significativa. Além disso, uma maior igualdade entre os conteúdos de FC e FMC e que estes últimos sejam melhor distribuídos nos três volumes das coleções de livros didáticos, não sobrecarregando o fim do volume 3 que é usado no $3^{\circ}$ do $E M$, viabilizando assim que sua inserção se dê durante todos os três anos do EM.

Quando as mesmas coleções são comparadas com suas edições do PNLEM 2009, pôde-se constatar, a partir da análise feita, que algumas obras traziam temas de FMC em seus livros, mas que eram bem diferentes entre si e não recebiam a mesma atenção que os outros conteúdos, como por exemplo: a coleção Compreendendo a Física, que apresenta conteúdos de Física Moderna em seu último capítulo, sem vínculo com as unidades anteriores, deixando claro o caráter complementar dado pelo autor, a qual nem mesmo o Guia do PLNEM 2009 cita que contém esses assuntos; e a coleção Física: Contexto e Aplicações, que contemplou tópicos acerca das partículas elementares, da física dos corpos de grande massa e de estruturas complexas. A coleção Física Ciência e Tecnologia destacou-se possuindo três capítulos que versam sobre a Relatividade Especial, Física Quântica e Física Nuclear.

Com o intuito de comparar as coleções analisadas quanto à quantidade de exercícios, elaborou-se também uma tabela com o quantitativo de exercícios propostos aos alunos e exercícios resolvidos que cada coleção apresenta nos capítulos que contemplam FMC. Não foram consideradas as eventuais questões que estão nos quadros complementares. A tabela 1 mostra os resultados, em que ' $P$ ' representa a quantidade de exercícios propostos e ' $R$ ' a quantidade de exercícios resolvidos. 
Tabela 1 - Quantitativo de exercícios nas coleções nos capítulos de FMC.

\begin{tabular}{|c|c|c|c|c|c|c|c|c|}
\hline \multirow{4}{*}{ COLEÇÃO } & \multicolumn{8}{|c|}{ QUANTIDADE } \\
\hline & \multirow{2}{*}{\multicolumn{2}{|c|}{$\begin{array}{c}\text { PNLEM } \\
2009\end{array}$}} & \multicolumn{6}{|c|}{ PNLD } \\
\hline & & & \multicolumn{2}{|c|}{2012} & \multicolumn{2}{|c|}{2015} & \multicolumn{2}{|c|}{2018} \\
\hline & $\mathbf{P}$ & $\mathbf{R}$ & $\mathbf{P}$ & $\mathbf{R}$ & $\mathbf{P}$ & $\mathbf{R}$ & $\mathbf{P}$ & $\mathbf{R}$ \\
\hline Compreendendo a Física & 0 & 0 & 48 & 16 & 40 & 20 & 21 & 8 \\
\hline Física Interação e Tecnologia & 0 & 0 & 23 & 2 & 36 & 3 & 41 & 5 \\
\hline Física: Contexto e Aplicações & 15 & 0 & 56 & 0 & 19 & 0 & 12 & 0 \\
\hline Física Ciência e Tecnologia & 77 & 16 & 107 & 15 & 70 & 16 & 66 & 13 \\
\hline
\end{tabular}

Fonte: Dados da pesquisa.

Os exercícios resolvidos, quando existem, são distribuídos ao longo dos capítulos ou, quando todos os exercícios são postos no fim do capítulo ou da unidade, eles também o são. Quanto à forma, se objetivos ou abertos, e local (posicionamento) dos exercícios propostos aos estudantes, elaborou-se um quadro para sintetizar os resultados, como observado a seguir no quadro 2.

Quadro 2 - Forma e local dos exercícios resolvidos nos capítulos de FMC das coleções.

\begin{tabular}{|l|c|c|}
\hline \multicolumn{1}{|c|}{ COLEÇÃO } & FORMA & LOCAL \\
\hline Compreendendo a Física & Grande parte abertos & $\begin{array}{c}\text { Decorrer dos capítulos e final } \\
\text { da unidade }\end{array}$ \\
\hline Física Interação e Tecnologia & Objetivos e abertos & $\begin{array}{c}\text { Final dos capítulos e da } \\
\text { unidade }\end{array}$ \\
\hline Física: Contexto e Aplicações & Grande parte objetivos & Decorrer e fim do capítulo \\
\hline Física Ciência e Tecnologia & Grande parte abertos & Decorrer e fim dos capítulos \\
\hline
\end{tabular}

Fonte: Dados da pesquisa.

Observa-se que a coleção Física Ciência e Tecnologia traz mais exercícios que as outras, tanto resolvidos como propostos, dando mais oportunidade aos alunos de testarem seus conhecimentos adquiridos, já a coleção Física: Contexto e Aplicações não possui exercícios resolvidos, impossibilitando os alunos a visualização dos procedimentos de resolução de questões problema. Verificou-se também que a maioria das coleções analisadas distribui os exercícios no decorrer dos capítulos, facilitando o aprendizado, pois os conhecimentos vão sendo adquiridos e testados por meio das questões à medida que se desenrola a leitura do texto.

Constatou-se que apenas a coleção Física Interação e Tecnologia tem uma quantidade balanceada de questões abertas e fechadas (objetivas) e as outras três possuem mais de um ou de outro. Considera-se aqui que o mais apropriado seria quantidades próximas entre as duas formas, pois, com os exercícios abertos, o alunado pode expressar-se com suas próprias palavras para tentar responder o problema, melhorando sua desenvoltura na medida em que se esforça para responder corretamente, à sua maneira. Já com exercícios objetivos (de múltipla 
escolha), eles têm a oportunidade de treinar o estilo de questões que são cobradas na maioria dos vestibulares do país.

Outro ponto observado é que a maioria das coleções diminuem a quantidade de exercícios e tópicos à medida que vão sendo atualizadas, isso permite questionar sobre quais motivos os levam os autores a assumir tal atitude. É certo que o tempo disposto para as aulas de Física do EM é pouco, duas aulas semanais na rede pública de ensino, visto à grande quantidade de conteúdos que estão previstos para esse nível de ensino, mas considera-se exercícios como uma boa forma de colocar o conhecimento adquirido em prática e, assim, os estudantes podem tentar resolvêlos fora de sala de aula. Nesse caso, quanto mais problemas, levando em consideração o nível e a qualidade, melhor para a fixação do aprendizado.

\section{CONSIDERAÇÕES FINAIS}

Para a realização desse trabalho, foi feita uma análise de quatro coleções didáticas de Física presentes no PNLEM 2009 e nos PNLDs 2012, 2015 e 2018. Teve como objetivo geral verificar como os tópicos de FMC estão presentes nos livros, bem como aferir as mudanças ao decorrer de suas atualizações. Para sua concretização, foram pesquisados, em escolas públicas e na internet, os volumes 3 de quatro coleções didáticas de Física que foram aprovadas nos programas citados, utilizando os Guias de cada plano como ponto de partida para a análise crítica de cada obra.

Através da análise das coleções didáticas de Física, pôde-se perceber que não há conteúdos de FMC pré-definidos para estarem presentes nos livros, o que ocasiona riqueza de tópicos em umas coleções e outras não e, além disso, eles acabam concentrados no final dos volumes 3 das coleções.

Os tópicos relacionados à Teoria da Relatividade Restrita e à Física Quântica são os que mais aparecem nos livros analisados. Entretanto, segundo a lista elaborada por Ostermann e Moreira (1998), há vários outros tópicos que poderiam ser abordados nesse nível de ensino, mas que não são contemplados pelos livros textos. Embora haja pesquisas elencando quais temas são possíveis de se ensinar no EM, não há um consenso entre as editoras e autores sobre quais tópicos devem figurar nos livros, acarretando uma carência de assuntos pertinentes à compreensão 
do mundo atual, o que pode comprometer aspectos relevantes da formação dos estudantes. Quando se analisa quais tópicos de Física Clássica estão presentes nos livros, percebe-se que todas as coleções tratam dos mesmos conteúdos, ou seja, há uma definição de quais assuntos de Física Clássica devem ser ensinados no EM. Tal fato revela-se como motivador de estruturação, por parte das editoras e autores, sobre quais tópicos são apropriados para esse nível de ensino e devem estar contidos nos livros, assim como o traçado de métodos e técnicas de inserção.

Outro ponto de destaque é que nem sempre as atualizações das edições dos livros didáticos ocasionam melhorias no sentido de aprimorar os conteúdos, posto que, no decorrer das atualizações, alguns tópicos de FMC perdem espaço nos livros. Não se objetiva aqui afirmar que essa perda de conteúdos é negativa, pois alguns conteúdos podem ser enxugados ou não são mesmo necessários seu estudo nos livros, no entanto, tal fato conduz a questionamentos acerca de quais fatores levam à sua exclusão, uma vez que outrora foram considerados pertinentes. Contudo, as coleções analisadas realizam uma boa abordagem dos conteúdos expostos, fazendo recortes históricos e sugerindo materiais complementares que dão suporte ao ensino, propondo experimentos que facilitam o processo de ensinoaprendizagem desses tópicos e introduzindo-os de forma contextualizada, com algumas ressalvas feitas pelos Guias dos PLNDs anteriormente citados. Além disso, observou-se também que, com exceção da coleção Física Ciência e Tecnologia, as outras 3 coleções analisadas tiveram suas principais mudanças na transição das edições do PNLEM 2009 para o PNLD 2012, sendo que, nesse último, os autores mostraram-se favoráveis quanto ao ensino de FMC no nível médio.

É relevante salientar que alguns livros que tratam de Física Clássica no ensino superior já trazem conteúdos de FMC, como por exemplo, o volume 1 da coleção dos autores Alonso e Finn, que trata sobre a Mecânica de Newton, contém Relatividade Restrita. Portanto, como os volumes 1 e 2 das coleções trazem assuntos de Física Clássica, tradicionalmente, essa tendência que começou a ser implantada nesse nível de ensino também é aplicável no EM, inserindo tópicos de FMC nesses volumes.

É importante ressaltar ainda a necessidade da introdução de tópicos de FMC nos demais volumes das coleções como uma forma de contextualizar os conteúdos e transmitir a noção de uma Física não fragmentada e não estagnada no tempo. Estes aspectos ficam claros durante o estudo das Teorias da Relatividade e da 
Mecânica Quântica. Essa contextualização pode ser feita de diversas formas, sobressaindo-se o método utilizado pela coleção Física Interação e Tecnologia, o qual dispõe de um quadro intitulado "Texto e interpretação" que discorre sobre como o assunto estudado no capítulo sofreu alterações com o surgimento da FM.

Observou-se que o fato de os tópicos de FMC estarem, quase sempre, concentrados nos últimos capítulos dos livros didáticos pode vir a deixá-los de fora das aulas durante o EM, dado que a carga horária é pequena e há uma grande diversidade de conteúdos propostos nos planos curriculares dos livros. Dessa forma, sugere-se que a introdução da FMC seja pontual, inserindo os temas nas três séries do EM sempre que houver uma relação com os conteúdos de Física Clássica, onde essa relação pode variar de acordo com o assunto ou a metodologia que o professor julgar mais efetiva. Além disso, propõe-se a criação de aulas interdisciplinares para que alguns temas sejam tratados por mais de uma disciplina, promovendo a interdisciplinaridade e contextualização nas escolas, ao passo que constrói uma imagem unificada da Ciência. Ademais, é preciso também que seja revista a carga horária da disciplina de Física no EM, pois mesmo que não sejam ensinados os tópicos de FMC, duas aulas semanais têm sido insuficientes para que todos os assuntos de Física previstos nos documentos oficiais sejam ensinados de forma significativa. Desta forma, para que a inserção de FMC seja relevante, necessita-se de mais aulas de Física no EM.

Soma-se a isso, a inexistência de questões do Enem relacionadas a esses tópicos, uma vez que ele é o principal meio de ingresso no ensino público superior e que as escolas, de um modo geral, visam prioritariamente o ingresso dos seus alunos nas instituições públicas do país. Tal fato pode estar relacionado com o questionamento citado anteriormente, visto que, embora os autores reconheçam a importância da inclusão de FMC no EM e tenham tendência a incluí-la em suas coleções, o que transparece é a intenção de serem sucintos em sua abordagem, pois esses conteúdos não serão cobrados no principal vestibular do país, que é adotado pela maioria das universidades públicas.

Considerando o caráter incessante da pesquisa por novos conhecimentos, sabe-se da importância do preenchimento de suas lacunas e propõem-se aqui sugestões de continuação, tais como: 
- Análise de todas as coleções presentes no PNLEM 2009 e nos PNLD's 2012, 2015 e 2018 quanto aos conteúdos de Física Moderna e Contemporânea, buscando uma melhor adequação do conteúdo para a Educação Básica;

- Pesquisar quais mudanças quanto ao estudo de FMC podem ser consideradas como motivos da retirada de algumas coleções do PNLD ao longo de suas edições;

- Elaborar minunciosamente uma lista com todos os tópicos que estão na lista proposta por Ostermann e Moreira (1998) e nos livros aprovados, pelo menos, no PNLD 2018, visto que esse é o plano mais recente e é a referência atual das escolas brasileiras.

\section{Referências}

BRASIL. Ministério da Educação. Física: Catálogo do Programa Nacional do Livro do Ensino Médio - PNLEM 2009, Brasília, 2008.

. Guia de livros didáticos: PNLD 2012 - Física. Brasília: MEC/SEB, 2011. . Guia de livros didáticos: PNLD 2015 - Física. Brasília: MEC/SEB, 2014. . Guia de livros didáticos: PNLD 2018 - Física. Brasília: MEC/SEB, 2017. . Ministério da Educação. Resolução CD/FNDE ํㅜ 38, de 15 de outubro de 2003. Diário oficial [da República Federativa do Brasil], Brasília, DF, n. 38 , 11 out. 2003. Seção?, p. 123-154.

DOMINGUINI, Lucas. Física moderna no Ensino Médio: com a palavra os autores dos livros didáticos do PNLEM. Revista Brasileira de Ensino de Física, São Paulo, v. 34, n. 2, p. 2502, jun. 2012.

GONÇALVES FILHO, A.; TOSCANO, C. Física. 1. ed. Scipione: São Paulo, 2007. 3 V.

Física e realidade. 1. ed. São Paulo: Scipione, 2011. 3 v. . Física Interação e Tecnologia. 1. ed. São Paulo: Leya, 2013. 3 v. . Física Interação e Tecnologia. 2. ed. São Paulo: Leya, 2016. 3 v.

FORQUIN, J. C. Escola e Cultura: As bases sociais e epistemológicas do conhecimento escolar. Tradução Guacira Lopes Louro. 1993. 208 f. Artes Médicas, Porto Alegre, 1993. 
GASPAR, A. Física. 1. ed. São Paulo: Editora Ática, 2005a. v. único.

. Física: manual do professor. In: GASPAR, Alberto. Física. 1. ed. Livro do Professor. São Paulo: Editora Ática, 2005b. v. único.

. Compreendendo a Física. 1. ed. São Paulo: Ática, 2011. 3 v.

. Compreendendo a Física. 2. ed. São Paulo: Ática, 2013. 3 v.

Compreendendo a Física. 3. ed. São Paulo: Ática, 2017. 3 v.

JÚNIOR, M. R. F.; CRUZ, F. F. S. Física Moderna e Contemporânea no Ensino Médio: do consenso de temas à elaboração de propostas. In:

ENCONTRO NACIONAL DE PESQUISA EM EDUCAÇÃO EM CIÊNCIAS, 4., 2003, Bauru. Atas... 2003.

MARTINS, V. R.; LEITE, C. Proposta curricular do estado de São Paulo: uma análise da contextualização sócio-cultural no tema da Física Moderna e Contemporânea. In: SIMPÓSIO NACIONAL DE ENSINO DE FÍSICA, 19., 2011, Manaus. Atas... 2011.

MAXIMINIANO, J. R.; CARDOSO, L.; DOMINGUINI, L. Física Moderna nos Livros Didáticos: um contraponto entre o PNLEM 2009 e o PNLD 2012. VIDYA, Santa Maria, v. 33, n. 1, p. 97-115, jan./jun. 2013.

MÁXIMO, A.; ALVARENGA, B. Física. 1. ed. São Paulo: Scipione, 2005. 3 v.

Manual do Professor. In: MÁXIMO, A.; ALVARENGA, B. Curso de Física. Livro do Professor, São Paulo: Scipione, 2010. 3 v.

. Curso de Física. 1. ed. São Paulo: Scipione, 2011. 3 v.

Física: Contexto \& Aplicações. 1. ed. São Paulo: Scipione, 2014.

$3 \mathrm{v}$.

MÁXIMO, A.; ALVARENGA, B. GUIMARÃES, Carla. Física: Contexto \& Aplicações. 2. ed. São Paulo: Scipione, 2016. 3 v.

MORAIS, A.; GUERRA, A. História e a filosofia da ciência: caminhos para inserção de temas de física moderna no estudo de energia na primeira série do Ensino Médio. Revista Brasileira de Ensino de Física, São Paulo, v. 35 n. 1 p. 1502 , fev. 2013.

MOREIRA, M. A. Aprendizagem Significativa: a teoria e textos complementares. São Paulo: Editora Livraria da Física, 2011.

MOTA, H. PNLD 2018: Principais Mudanças no Programa do Livro Didático.

Brasil Escola. Disponível em:

$<$ https://educador.brasilescola.uol.com.br/politica-educacional/pnld-2018- 
principais-mudancas-no-programa-livro-didatico.htm>. Acesso em: 25 abr. 2018.

OSTERMANN, F.; MOREIRA, M. A.; Tópicos de Física Contemporânea na Escola Média: um Estudo com a Técnica Delphi. In: Encontro de Pesquisadores em Ensino de Física, 6., 1998, Florianópolis. Atas...1998.

PENTEADO, P. C. M.; TORRES C. M. A. Física: Ciência e Tecnologia. 1. ed. São Paulo: Moderna, 2005. 3 v.

SALES, N. L. L. Problematizando o ensino de Física Moderna e Contemporânea na formação continuada de professores: análise das contribuições dos três momentos pedagógicos na construção da autonomia docente. 2014. 217 f. Tese de Doutorado - Universidade de São Paulo, São Paulo, 2014.

TORRES, C. M. A.; FERRARO, N. G.; SOARES, P. A. de T. Física: Ciência e Tecnologia. 2. ed. São Paulo: Moderna, 2010. 3 v.

TORRES, C. M. A. et al. Física: Ciência e Tecnologia. 3. ed. São Paulo: Moderna, 2013. 3 v.

$3 \mathrm{v}$.

. Física: Ciência e Tecnologia. 4. ed. São Paulo: Moderna, 2016. 